\title{
Tribological characteristics of friction stir processed graphite and tin/LM24 surface composites
}

\author{
Vipin SHARMA, Ujjwal PRAKASH, B. Venkata MANOJ KUMAR* \\ Department of Metallurgical and Materials Engineering, Indian Institute of Technology Roorkee, Roorkee 247667, India \\ Received: 09 October 2019 / Revised: 21 March 2020 / Accepted: 24 May 2020 \\ (C) The author(s) 2020.
}

\begin{abstract}
Friction stir processing (FSP) is an emerging solid-state technique for preparing surface composites using various reinforcements. Ceramics and metallic particles are easily reinforced in a matrix by this technique. Surface composites made from an LM24 alloy reinforced with graphite and tin, with good wettability and material flow owing to the low melting point of tin, were fabricated by FSP at two rotational speeds of 1,400 and 1,000 rpm. Despite its low hardness, the graphite/LM24 surface composite fabricated at a higher rotational speed of 1,400 rpm exhibited better wear resistance. However, its frictional behavior was not significantly affected by the reinforcement. The fabricated surface composites with graphite and tin reinforcement as well as graphite-only reinforcement exhibited contradicting behaviors under sliding wear conditions. The post wear analysis indicated that abrasion, adhesion, layer formation, and delamination occurred on the composite surfaces.
\end{abstract}

Keywords: composites; friction stir processing; graphite; tin; Al-Si alloy; wear

\section{Introduction}

Al-Si alloys are often used in several engineering applications owing to their high strength-to-weight ratio, low coefficient of thermal expansion, and better wear resistance as compared to other aluminum alloys [1-4]. However, the porosity and needle or acicular morphology of the $\mathrm{Si}$ are detrimental to its mechanical properties [5, 6]. Al-Si alloys can be tailored by alloying, microstructural modification, or reinforcing with suitable reinforcements to improve their performance in engineering applications [7].

Friction stir processing (FSP) is an emerging technique for microstructural refinement and surface composite fabrication [8-10]. Conventional techniques for fabricating metal matrix composites, such as liquid melt stirring and powder metallurgy, have various pertinent issues. The metal matrix composites fabricated using the liquid melt stirring technique are limited by the agglomeration of the reinforcement particles, poor wettability, and interfacial reaction product phases [4, 9]. Meanwhile, the residual porosity and non-uniform distribution of the reinforcement particles are significant issues in composites fabricated by the powder metallurgy technique. Moreover, the powder metallurgy route is expensive and high energy-consuming [11]. In addition, the composites fabricated by these conventional techniques exhibit poor mechanical properties and often fail to serve their intended purpose in engineering applications. On the other hand, FSP results in microstructural refinement and uniform distribution of the second phase constituents. As FSP is a solid-state technique, there is a low possibility of interfacial reactions between the reinforcement and matrix $[9,10]$. FSP effectively breaks the acicular Si to near-spherical

* Corresponding author: B. Venkata MANOJ KUMAR, E-mail: manoj.kumar@mt.iitr.ac.in 
Si and homogenizes the dendrite network, thereby improving the mechanical properties of the cast alloys and Al-Si alloys [9]. In a comparison study, Yuvaraj et al. [12] used tungsten inert gas arc (TIG) and FSP to fabricate a $\mathrm{B}_{4} \mathrm{C} / \mathrm{AA} 5083$ composite. They found that the high temperature used in the TIG route caused grain coarsening and interfacial reactions between the matrix and reinforcement. During FSP, the average grain size was reduced from $49.5 \mu \mathrm{m}$ in the base alloy to $3 \mu \mathrm{m}$ in the composite owing to dynamic recrystallization. The grain refinement and uniform distribution of the reinforcement particles resulted in the improved wear resistance of a composite produced by FSP.

Previous studies on the Al-Si alloys produced by FSP demonstrated that the size of the acicular Si particles could be decreased to submicron size $[13,14]$. During the composite fabrication of the Al-Si alloys, FSP results in the breaking up of the acicular $\mathrm{Si}$, reduction in the grain size, and uniform distribution of the reinforced particles [14]. Several reinforcements such as $\mathrm{Al}_{2} \mathrm{O}_{3}, \mathrm{SiC}, \mathrm{B}_{4} \mathrm{C}, \mathrm{TiC}, \mathrm{MoS}_{2}$, and graphite have been used to prepare surface composites via the FSP route $[9,15]$. Meanwhile, solid lubricants are widely used to improve the tribological behavior of metal matrix composites. Graphite is a typical solid lubricant used in the fabrication of composites as it reduces the frictional forces and enhances the tribological properties [16, 17]. Zhu et al. [18] observed that solid lubricant particles $\mathrm{WS}_{2}$ in spark-plasma-sintered $\mathrm{SiC}_{-} \mathrm{WS}_{2}-$ $\mathrm{Mg}$ composites spread on the surface, forming a tribolayer during the reciprocating sliding. This tribolayer prevents the transition of the wear mechanism from abrasion to delamination. The layered structure of the $\mathrm{WS}_{2}$ particles easily sheared from the micro-scale to the nano-scale, resulting in a reduction in the coefficient of friction (COF) and wear of the composite. Wang et al. [19] studied the effect of adding silver on the tribological characteristics of $\mathrm{Cu}-\mathrm{Ni}$-graphite composites. They found that adding silver enhances the lubrication effect. The $\mathrm{COF}$ and wear loss of silver-modified $\mathrm{Cu}-\mathrm{Ni}$-graphite composite were lower than those of the $\mathrm{Cu}-\mathrm{Ni}-$ graphite composite. In addition, the wear resistance of the silver-modified composite was approximately 91\% higher than that of the unmodified $\mathrm{Cu}-\mathrm{Ni}-$ graphite composite. The improvement in the tribological characteristics was attributed to the soft silver metal, which deformed easily and contributed to the lubricating film formation on the surface.

A study conducted by Qiu et al. [20] revealed that the sliding conditions determine the wear behavior of FeAl during sliding instead of its mechanical properties. The hardness of the composites decreased with increase in the graphite content. However, the wear resistance increased regardless of the reduction in the hardness owing to the favorable role of graphite in the tribolayer formation [21-23]. Marcinauskas et al. [24] found that the COF was reduced when the graphite- $\mathrm{Al}_{2} \mathrm{O}_{3}$ coating on the steel had a limited graphite content. A higher graphite content tends to reduce the hardness of the composite coating, which in turn increases the possibility of $\mathrm{Al}_{2} \mathrm{O}_{3}$ pull-out. However, an inverse correlation of the wear to the hardness of the composite layer has been observed in the $\mathrm{FeNi}$ graphite composite layer [25]. The hardness of the FeNi-graphite composite layer decreased when the softer graphite content was increased. However, the composite layer exhibited better wear resistance at an optimum graphite content [25].

In engineering applications, tin is commonly added to improve the frictional behavior of a contact surface. Tin is a softer metal owing to its low shear strength; therefore, it readily forms a film under a deforming load, which protects the underlying surface from wearing out easily. As a result, tin is frequently used to prevent seizure in bearings when the system runs out of lubrication. Tin is also known for its anti-welding characteristics with iron, thus reduces the possibility of adhesive wear [26, 27]. During FSP, the homogeneous distribution of the reinforced particles and formation of a defect-free composite surface depends on the material flow [9, 10]. The liquid phase, which is made up of tin with a low melting point, enhances the fluidity and improves the material flow. On the other hand, the enhanced wettability provided by the liquid phase improves the bonding of the reinforcement particles with the matrix. Therefore, the addition of tin is 
recommended to improve the wettability and material flow in the processed zone of the graphite/aluminum alloy composites.

However, to the knowledge of the authors, tribological characteristics of surface composites with graphite and tin reinforcement are hardly reported. In the present study, graphite and tin were used as reinforcements in the Al-Si alloy (LM24) composite prepared using the FSP route. The effects of adding graphite and tin on the sliding wear properties in correlation with the rotational speed during the FSP, and applied load during the sliding wear test are discussed.

\section{Experimental methods}

In this study, $120 \mathrm{~mm} \times 60 \mathrm{~mm} \times 6 \mathrm{~mm} \mathrm{Al-Si}$ alloy LM24 (Si-8, Cu-3.6, Zn-2.6, Fe-0.9, Mn-0.5, Pb-0.35, $\mathrm{Mg}-0.3$, Sn-0.2 wt\%, with the balance being $\mathrm{Al}$ ) plates were used for preparing the composites via the FSP route. Figure 1 shows a schematic illustration of the composite fabrication process via the FSP route. Graphite flakes and tin particles $(\sim 50 \mu \mathrm{m})$, used as reinforcements, were mixed using a doubleaxis rotary mill for $2 \mathrm{~h}$. A vertical milling machine (Hindustan Machine Tools, India) was then used for performing the FSP. An H13 steel (55 HRC) tool, with a concave shoulder of $21 \mathrm{~mm}$ in diameter, and a conical-shaped probe with the diameter reducing from $5 \mathrm{~mm}$ at the top to $3 \mathrm{~mm}$ at the bottom were used during the FSP. A four-pass FSP, at rotational speeds of 1,000 and $1,400 \mathrm{rpm}$ at a constant traverse speed of $63 \mathrm{~mm} / \mathrm{min}$, was performed by clockwise rotation of the tool. The details of the surface composite fabrication and process parameters are listed in Table 1. For metallographic examination, the specimens were prepared using a standard grinding and polishing technique. Then, the polished surfaces were etched using a modified Poulton's reagent. The microstructure of the material after FSP was studied using a LEICA DMI 5000M microscope and Zeiss scanning electron microscope (SEM). A Vickers microhardness tester was used to indent the polished surfaces using a $200 \mathrm{gf}$ load for $15 \mathrm{~s}$ to determine their microhardness.

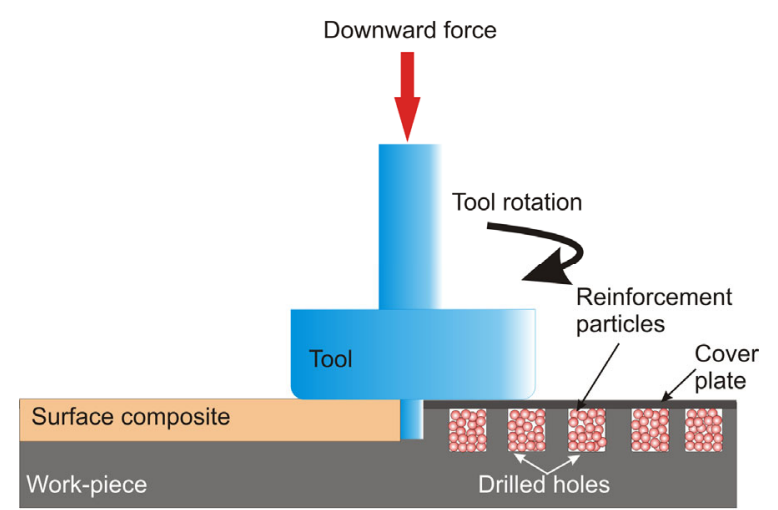

Fig. 1 Schematic illustration of surface composite fabrication by FSP.

Table 1 Details of reinforcements and tool speeds of LM24 surface composites.

\begin{tabular}{lcc}
\hline Reinforcements & $\begin{array}{c}\text { Rotational } \\
\text { speed }(\mathrm{rpm})\end{array}$ & $\begin{array}{c}\text { Traverse speed } \\
(\mathrm{mm} / \mathrm{min})\end{array}$ \\
\hline $\begin{array}{l}\text { Graphite } \\
50 \mathrm{wt} \% \text { graphite }\end{array}$ & 1,400 & 63 \\
$+50 \mathrm{wt} \%$ tin & 1,400 & 63 \\
$\begin{array}{l}50 \mathrm{wt} \% \text { graphite } \\
+50 \mathrm{wt} \% \text { tin }\end{array}$ & 1,000 & 63 \\
Graphite & 1,000 & 63 \\
\hline
\end{tabular}

The wear tests were conducted using a ball-ondisk wear tester (TR-201E, DUCOM) under ambient conditions $\left(25 \pm 5{ }^{\circ} \mathrm{C}\right.$ and $35 \% \pm 5 \%$ relative humidity $(\mathrm{RH})$ ). A schematic illustration of the ball-on-disk test configuration is presented in Fig. 2. A $6 \mathrm{~mm}$ diameter AISI52100 steel ball (60 HRC) was used as the counterbody. The steel ball was placed in a ball holder resulting in a radius of $1.5 \mathrm{~mm}$ on the disc. As the width of the composite zone formed by the FSP was $5 \mathrm{~mm}$, the wear track diameter was limited to $3 \mathrm{~mm}$. The sliding tests were carried using loads of 5 and $20 \mathrm{~N}$ at a constant speed of $0.0785 \mathrm{~m} / \mathrm{s}$ for $25 \mathrm{~min}$ (total sliding distance of $117.75 \mathrm{~m}$ ). The frictional force was recorded online and the COF was consequently calculated. After the wear test, the scar width and depth were measured to estimate the wear volume, hence the wear rate.

\section{Results and discussion}

\subsection{Microstructure}

The base alloy LM24 micrographs and fabricated 
surface composites are shown in Figs. 3(a)-3(e). The base alloy had an acicular eutectic Si of 20 to $60 \mu \mathrm{m}$ in size along with intermetallic phases, as shown in Fig. 3(a). Figure 3(b) shows the graphite/ LM24 surface composite stir zone (SZ) fabricated at 1,400 rpm. Figure 3(b) also shows that there is a significant refinement of the acicular Si size. Meanwhile, the SZ of the surface composite (graphite + tin)/LM24 fabricated at 1,400 rpm had a homogeneous distribution of particles (Fig. 3(c)). The reinforcement particles were uniformly distributed because of the stirring action of the rotating tool. The (graphite + tin)/ LM24 composite fabricated at 1,000 rpm had bands of reinforcement on the retreating side of the SZ owing to the low melting point tin reinforcement (Fig. 3(d)). However, uniformly distributed particles were observed in the SZ. Figure 3(e) shows the uniformly distributed and clustered graphite particles in the SZ of the graphite/LM24 surface composite fabricated at 1,000 rpm. At a low rotational speed, less heat was generated in the processed zone, which resulted in poor material flow.

\subsection{Microhardness values of the surface composites}

The microhardness values of the LM24 alloy and surface composites are presented in Fig. 4. The average microhardness of the LM24 alloy was $120 \mathrm{HV}$, while the surface composites had a microhardness values in the range of 106-118 HV. The graphite/ LM24 surface composites fabricated at 1,000 and $1,400 \mathrm{rpm}$ had the lowest microhardness values of 107 and $110 \mathrm{HV}$, respectively. Meanwhile, the microhardness values of the (graphite + tin)/LM24 surface composite fabricated at 1,000 and 1,400 rpm were 114 and $118 \mathrm{HV}$, respectively. The microhardness values of the surface composites were less than that

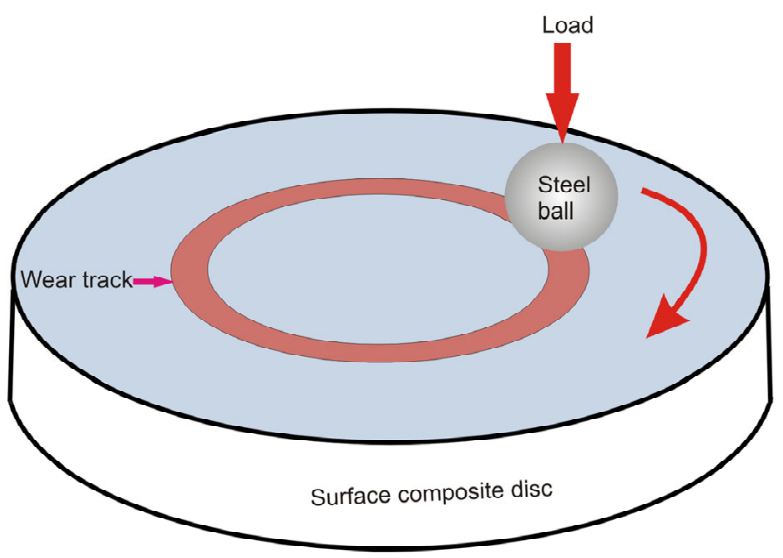

Fig. 2 Schematic illustrations of ball-on disc wear testing setup.
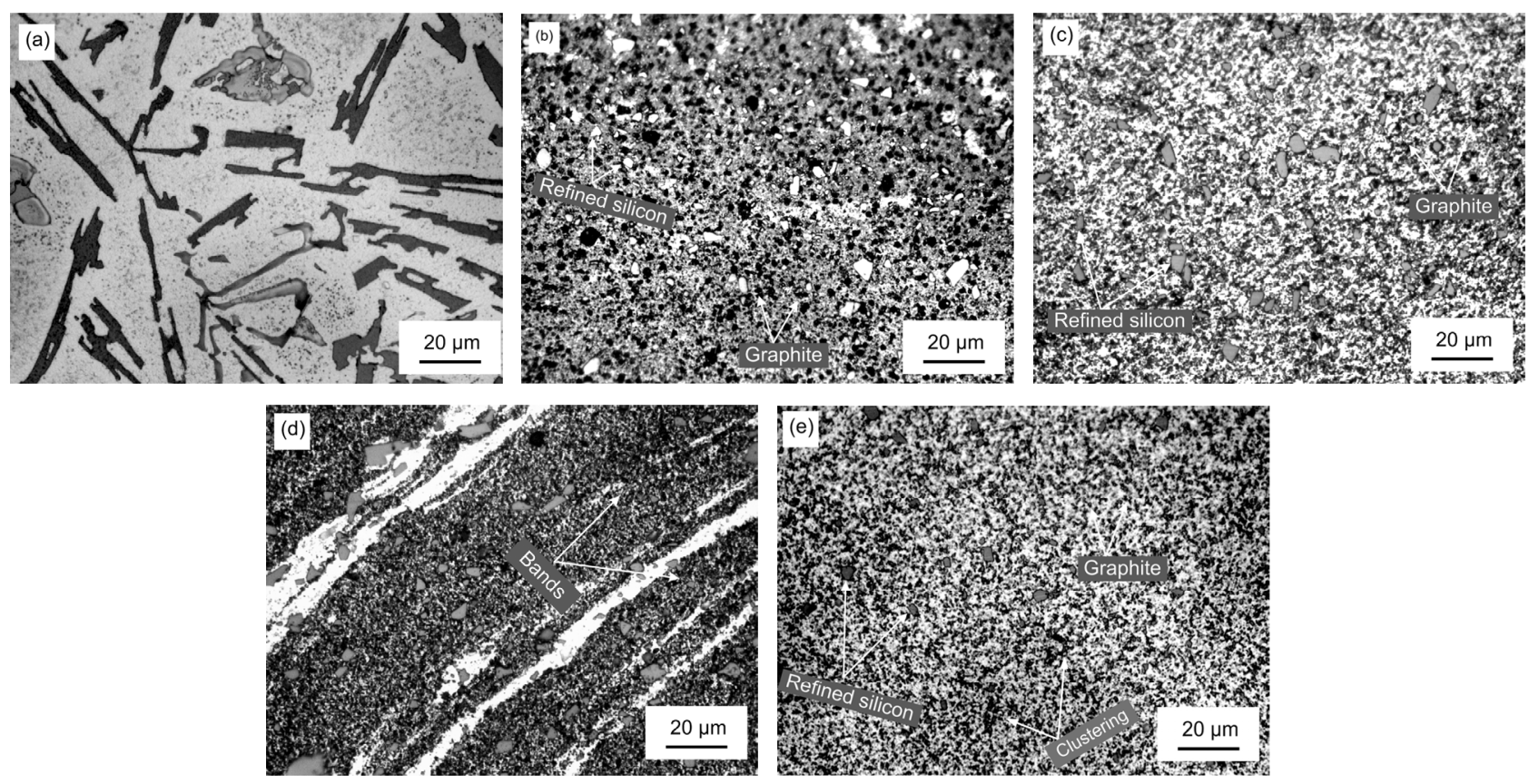

Fig. 3 Optical micrographs of (a) base alloy, (b) stir zone of surface composite graphite/LM24 fabricated at 1,400 rpm, (c) stir zone of surface composite (graphite + tin)/LM24 fabricated at 1,400 rpm, (d) bands of reinforcements in surface composite $($ graphite $+\operatorname{tin}) / L M 24$ fabricated at 1,000 rpm, and (e) stir zone of surface composite graphite/LM24 fabricated at 1,000 rpm. 


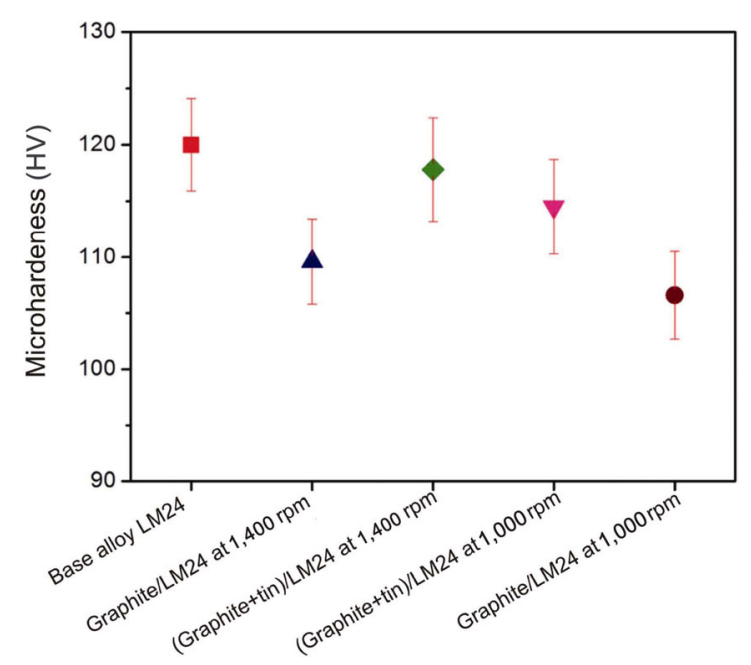

Fig. 4 Microhardness of base alloy and surface composites.

of the base alloy due to the softer reinforcements. The poor material flow owing to the low rotational speed of $1,000 \mathrm{rpm}$ resulted in a reduction in the microhardness. The higher hardness of the (graphite + tin)/LM24 composite was attributed to the lower graphite content and higher rotational speed. Devaraju et al. [28] reported that the hardness decreased as the graphite content increased in ( $\mathrm{SiC}+$ graphite)/

\section{(a)}

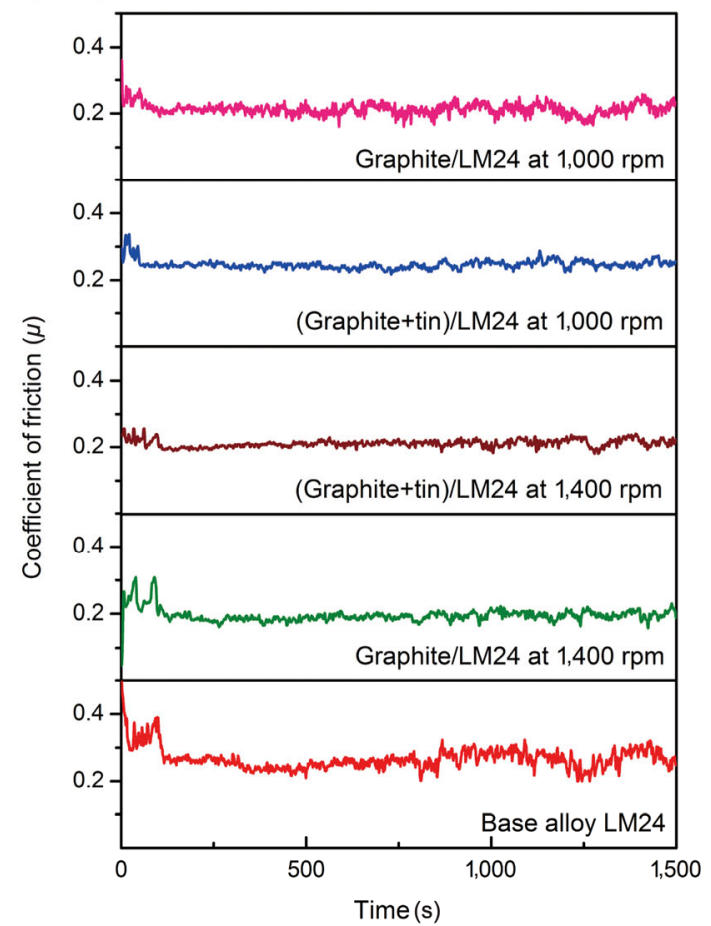

AA6061 hybrid surface composites fabricated by FSP. Meanwhile, the reduction in the dislocation density was ascribed to the reduction in the hardness of the Al-Si alloys after FSP [21].

\subsection{Friction characteristics of the surface composites}

The COF $(\mu)$ plots for the base alloy and surface composites at 5 and $20 \mathrm{~N}$ sliding loads are presented in Figs. 5(a) and 5(b), respectively. The average COFs of the base alloy and surface composites at different loads are shown in Fig. 6. The COFs at 5 $\mathrm{N}$ load (Fig. 5(a)) and $20 \mathrm{~N}$ (Fig. 5(b)) reached steady state after a period of $\sim 100 \mathrm{~s}$ and $\sim 200 \mathrm{~s}$, respectively. The COF plot at $20 \mathrm{~N}$ load has more fluctuations than that at $5 \mathrm{~N}$ load due to the easy removal of the material. As shown in Fig. 6, the average COFs of the base alloy were 0.22 and 0.27 at 5 and $20 \mathrm{~N}$ load, respectively. Meanwhile, the COF of the surface composites at a lower load of 5 $\mathrm{N}$ varied from 0.20 to 0.24 , whereas it varied from 0.23 to 0.26 at a higher load of $20 \mathrm{~N}$. Among the surface composites, the graphite/LM24 surface composite fabricated at $1,400 \mathrm{rpm}$ had low average

(b)

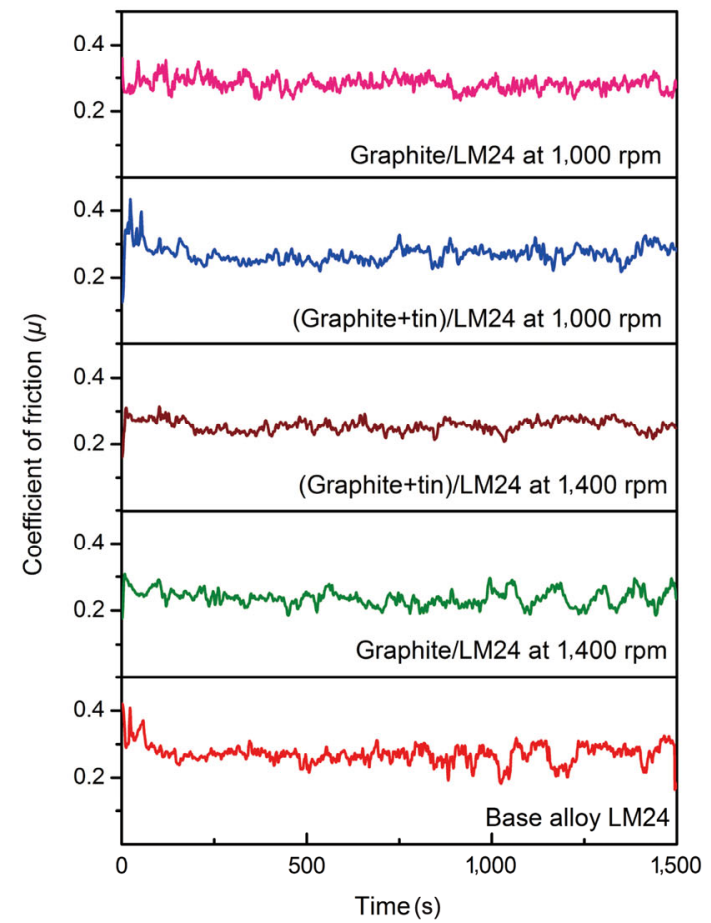

Fig. 5 Typical coefficient of friction $(\mu)$ vs. time plots for base alloy and surface composites slid against steel ball at (a) $5 \mathrm{~N}$ load and (b) $20 \mathrm{~N}$ load. 
COFs of 0.20 and 0.24 at 5 and $20 \mathrm{~N}$ load, respectively. This can be ascribed to the solid lubricating effect of the graphite only reinforcement. However, the surface composite with graphite only reinforcement fabricated at 1,000 rpm had a higher COF due to the clustering of the graphite.

At 5 and $20 \mathrm{~N}$ loads, the graphite/LM24 fabricated at 1,400 rpm had a lower COF than the graphite/LM24 fabricated at 1,000 rpm (as shown in Fig. 6). This indicates that the rotational speed is an essential parameter during the fabrication of the composites by FSP. The reduction in the COF of the composite fabricated at higher rotational speed can be attributed to the improved efficacy of graphite owing to the uniform distribution. At higher rotational speed, clusters of reinforcement particles were broken, resulting in a uniform distribution of the particles. The uniformly distributed graphite then formed a stable lubricating layer on the surface. The high rotational speed during the FSP results in high strain energy, high heat generation, size reduction and uniform distribution of particles, and better material flow $[9,28]$. The variation in the COF of the (graphite + tin)/LM24 composites fabricated at 1,000 and 1,400 rpm was not significant, which suggests that tin was not effective in reducing the COF compared to graphite. This was because of the difficulty in smearing the metallic tin particles during sliding.

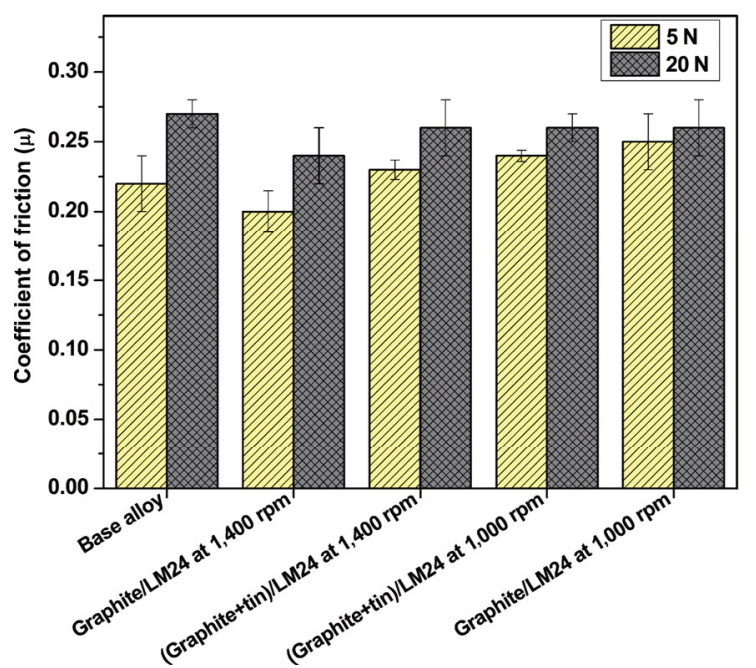

Fig. 6 Average COF of the base alloy and surface composites at different loads.

\subsection{Wear rate of the surface composites}

There was a significant variation in the wear rate of the composites fabricated at 1,000 and 1,400 $\mathrm{rpm}$, as shown in Fig. 7. The wear resistance of the composites fabricated at $1,400 \mathrm{rpm}$ was superior to that of composites fabricated at 1,000 rpm. However, the difference in the wear resistances was notable at a higher load. At a load of $5 \mathrm{~N}$, the wear rates of the graphite/LM24 composite fabricated at 1,400 and 1,000 rpm were $1.8 \times 10^{-3}$ and $2.5 \times 10^{-3} \mathrm{~mm}^{3} / \mathrm{m}$, respectively. When the load was increased to $20 \mathrm{~N}$, the wear rates increased to $5.0 \times 10^{-3}$ and $14.6 \times 10^{-3}$ $\mathrm{mm}^{3} / \mathrm{m}$, respectively. This indicates that at a higher load, the wear resistance of the graphite/LM24 composite fabricated at 1,400 rpm was approximately three times superior to that of the composite fabricated at 1,000 rpm.

At a lower load of $5 \mathrm{~N}$, the (graphite + tin)/LM24 composites fabricated at 1,400 and 1,000 rpm had wear rates of $1.9 \times 10^{-3}$ and $2.3 \times 10^{-3} \mathrm{~mm}^{3} / \mathrm{m}$, respectively. When the load was increased to $20 \mathrm{~N}$, the wear rates increased to $6.6 \times 10^{-3}$ and $13.5 \times 10^{-3}$ $\mathrm{mm}^{3} / \mathrm{m}$, respectively. Thus, at a higher load, the wear resistance of the (graphite + tin)/LM24 composite fabricated at 1,400 rpm was twice as superior as that of the composite fabricated at 1,000 rpm. Therefore, a reduction in the graphite content of the (graphite + tin)/LM24 composite significantly affected the wear resistance. The improvement in

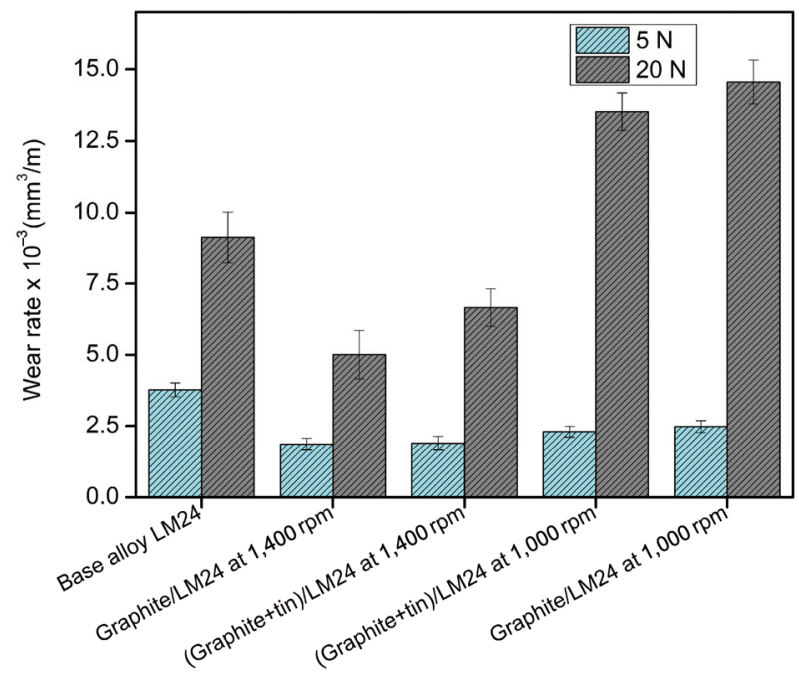

Fig. 7 Wear rate of the base alloy and surface composites at 5 and $20 \mathrm{~N}$ loads. 
the wear resistance at $1,400 \mathrm{rpm}$ can be attributed to the formation of a uniform thin layer, which prevented metal to metal contact. More heat generated at $1,400 \mathrm{rpm}$ than at $1,000 \mathrm{rpm}$ resulted in better material flow and uniform distribution of the reinforcement particles. It is also possible that the acicular Si was refined due to the increased shattering effect at a high speed of $1,400 \mathrm{rpm}$. The refined Si improves wear resistance since acicular $\mathrm{Si}$ is prone to crack formation when a load is applied.

Meanwhile, the wear resistance of the composite fabricated at 1,000 rpm was inferior to that of the base alloy at a load of $20 \mathrm{~N}$. In addition, the wear rate of the base alloy at a load of $20 \mathrm{~N}$ load was $9.1 \times 10^{-3} \mathrm{~mm}^{3} / \mathrm{m}$, which was superior to that of the composite fabricated at 1,000 rpm. Therefore, fabrication of the composites at a lower rotational speed of $1,000 \mathrm{rpm}$ is not beneficial because of the low heat generated and poor material flow. The poor material flow results in the clustering and weak bonding of the reinforcement particles, leading to their easy removal during sliding.

However, the wear resistance of the graphite/ LM24 composite fabricated at 1,400 rpm was superior despite its lower hardness than that of the base alloy and (graphite + tin)/LM24 composites. This can be attributed to the role of graphite in forming a lubricating layer during the sliding contact. The wear behavior of the composite containing solid lubricants is governed by the formation of a tribolayer; therefore, a detailed explanation of the tribolayer formation is provided in a later section.

\subsection{Wear mechanisms at a low load}

The worn surfaces of the base alloy and surface composites at $5 \mathrm{~N}$ load, that reveal the flow of material, are shown in Fig. 8. It was also observed that the matrix material adhered to the counterbody surface. At the contact point, the asperities flattened, and the material flowed due to the plowing of the steel ball. The layer formed with plowing marks in the sliding direction on the worn surface of the base alloy indicates flow wear (Fig. 8(a)). The microcracks perpendicular to the sliding direction suggest the occurrence of delamination wear on the base alloy (Fig. 8(b)). The worn graphite/LM24 surface composite fabricated at $1,400 \mathrm{rpm}$ had shallow plowing marks and layer deformation (Fig. $8(\mathrm{c})$ ). The graphite formed a lubricating layer that prevented metal to metal contact. However, in the absence of a continuous layer, mild adhesion is likely to occur and material would be transferred onto the counterbody. The presence of crater regions (Fig. 8(c)) confirms that material was removed by the adhesive wear of the graphite/LM24 surface composite. Figure $8(\mathrm{~d})$ shows a worn surface of the (graphite + tin)/LM24 composite fabricated at 1,400 rpm on which shallow plowing marks with disintegrated oxide particles (bright features) are visible. These oxide particles originated from either the tribolayer or mechanically mixed layer (MML). During continuous sliding of a ductile material, the initially transferred fragments of the material are mechanically mixed, deformed, fractured, and blended, to form an MML on the sliding surfaces. The disintegrated wear particles, with both shallow and deeper plowing marks, were visible on the (graphite + tin)/LM24 composite fabricated at 1,000 $\mathrm{rpm}$. The disintegrated wear particles act as abrasives or consolidate to form an MML. Figure 8(e) shows the worn surface of the graphite/LM24 composite fabricated at 1,000 rpm. The plowing marks and removal of material from the ridges of the plowing marks were observed. The ridges protruded and made contact with the counterbody steel ball.

A typical energy dispersive X-ray spectroscopy (EDS) analysis of the worn surfaces of the composites and counterbody is shown in Fig. 9. The EDS analysis (Fig. 9(a)) shows a high oxygen content on the worn surface of the graphite/LM24 surface composite fabricated at 1,400 rpm. The worn surface of the (graphite + tin)/LM24 composite fabricated at 1,000 rpm had highly oxidized and disintegrated wear particles (Fig. 9(b)). The worn surface of the counterbody that slid against the graphite/LM24 surface composite fabricated at 1,000 rpm had the transferred matrix material on it (Fig. 9(c)). The high oxygen content suggests that the oxidative wear mechanism worked together with abrasive and adhesive wear. The repeated sliding and removal of material accelerated the oxidation process. The small quantity of the counterbody material (iron) 
( $<1 \mathrm{wt} \%)$ suggests the absence of an MML at a load of $5 \mathrm{~N}$. After analyzing the worn surfaces at a low load of $5 \mathrm{~N}$, it can be concluded that abrasive wear, oxidative wear, and adhesive wear mechanisms are operative in the surface composites, while abrasive wear, adhesive wear, and delamination wear are dominant in the base alloy.

\subsection{Wear mechanisms at a high load}

The worn surfaces of the base alloy and surface composites at a high load of $20 \mathrm{~N}$ are shown in Fig. 10. At a higher load of $20 \mathrm{~N}$, microcracks easily generate and interlink into many wear particles by delamination. During delamination wear, material is removed by subsurface crack nucleation followed by crack propagation to the surface layer $[29,30]$. The worn surface of the base alloy had deeper plowing marks and microcracks. The deeper plowing marks are indicative of the abrasive wear due to contact with asperities or trapped wear particles during sliding. The worn graphite/LM24 surface composite prepared at 1,400 rpm had a delaminated surface and smooth surface with microcracks (Fig. 10(a)). The readily detachable material on the worn surface suggests the interlinking of the microcracks. The disintegrated fine wear particles found on the worn surface indicate the trapping of debris during contact. Repeated sliding caused the microcracks
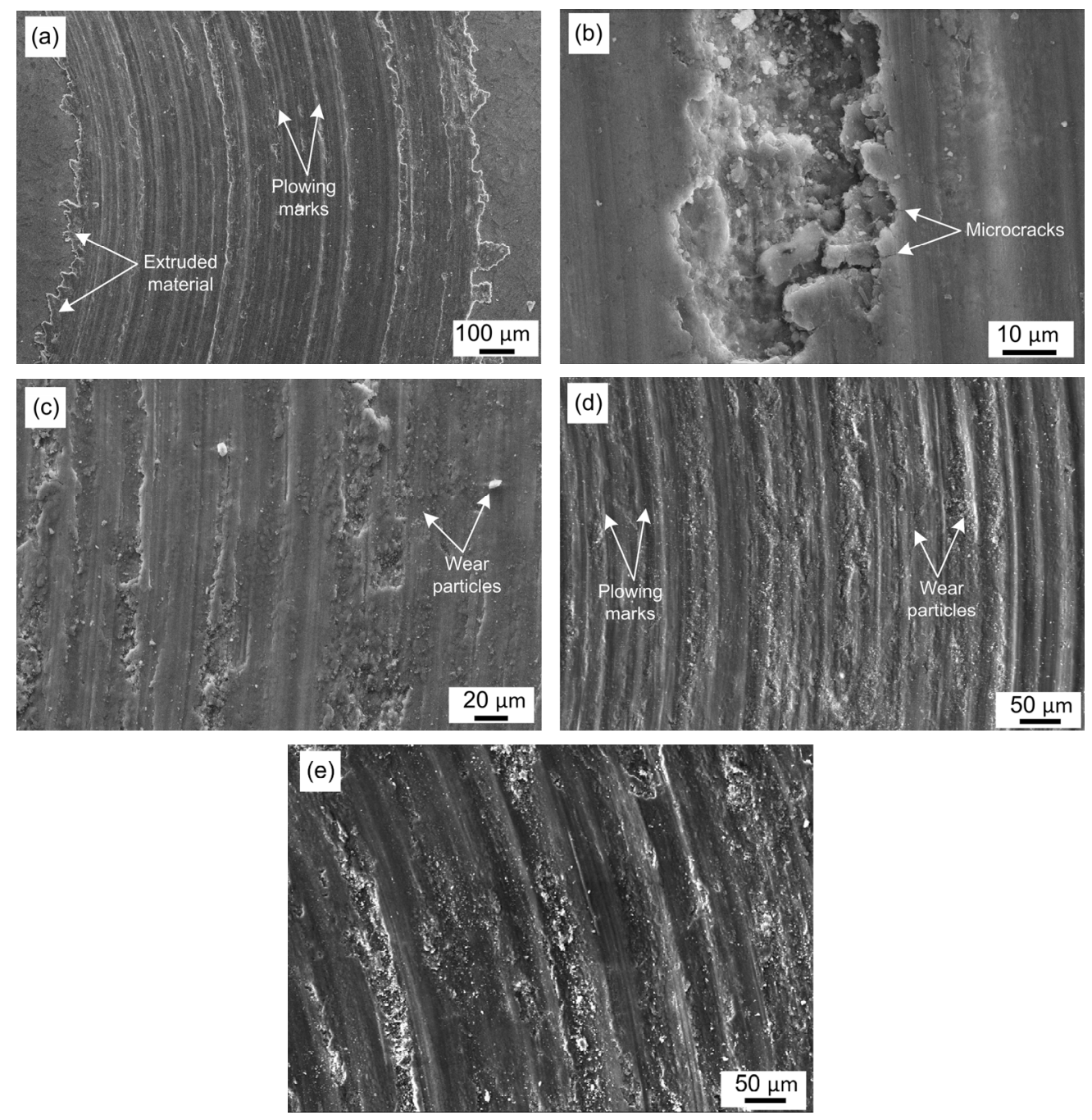

Fig. 8 SEM micrographs of worn surface of base and surface composites slid at $5 \mathrm{~N}$ load: (a) base alloy exhibiting flow wear, (b) microcrack formation in base alloy, (c) surface composite graphite/LM24 fabricated at 1,400 rpm, (d) (graphite + tin)/LM24 fabricated at 1,400 rpm, and (e) surface composite graphite/LM24 fabricated at 1,000 rpm. 
to propagate perpendicularly to the sliding direction and interlink on the upper surface layer. The smearing of graphite provided a lubricating layer, which limited the adhesion of the contacting surfaces. However, the graphite was not useful in preventing delamination wear. The worn (graphite + tin)/LM24 surface composite fabricated at $1,400 \mathrm{rpm}$ reveals a delaminated surface with deeper plowing marks (Fig. 10(b)). Meanwhile, the worn surface of the (graphite + tin)/LM24 surface composite fabricated at 1,000 rpm exhibits microcracks and delamination (Fig. 10(c)). A deformed layer with microcracks was also found on the worn surface. The worn graphite/ LM24 surface composite fabricated at 1,000 rpm had a delaminated surface with disintegrated wear particles (Fig. 10(d)). The fine plowing marks observed on the worn surface indicate third body abrasion by the trapped wear particles.
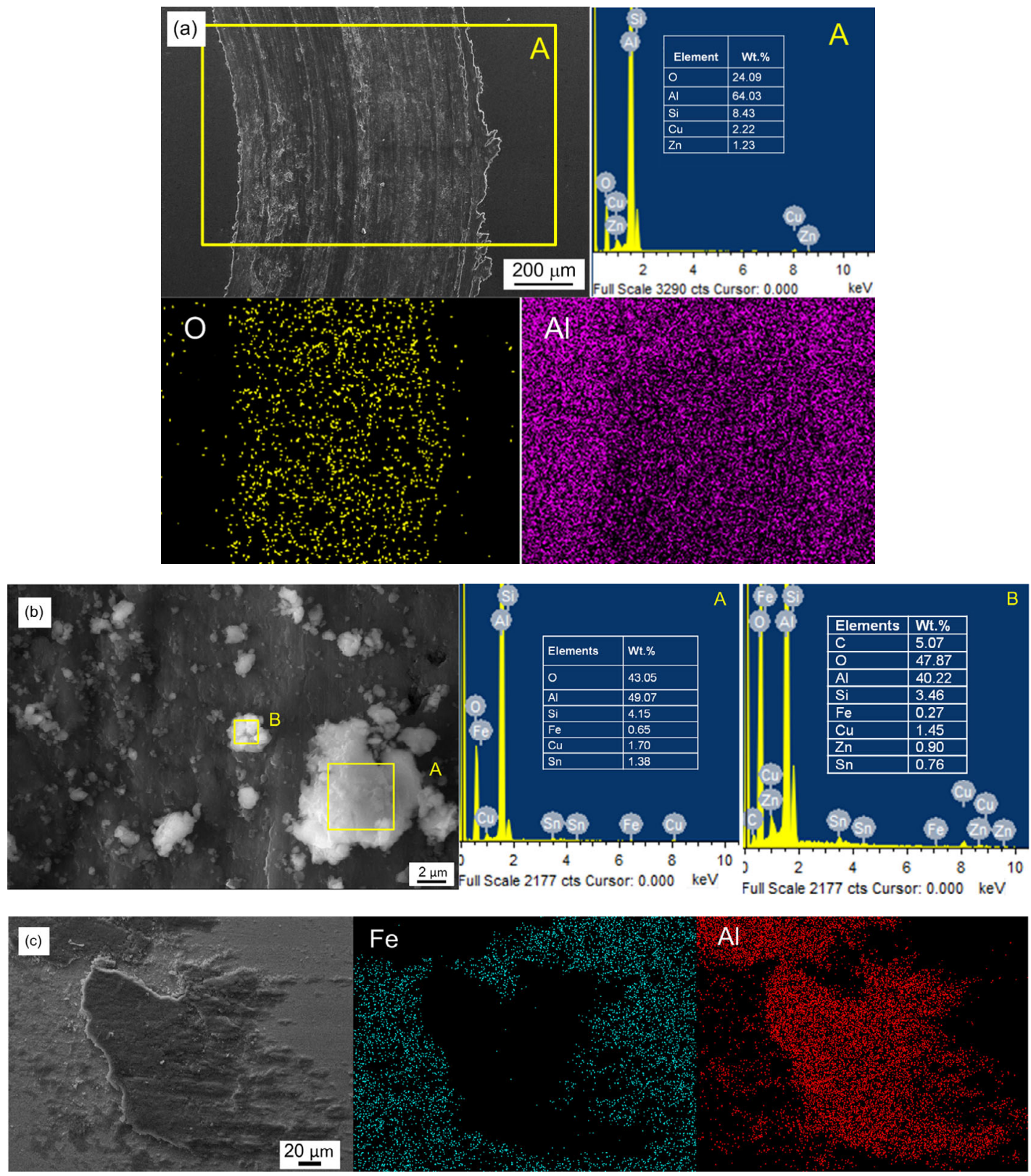

Fig. 9 EDS analysis of worn surface of composites and counterbody slid at $5 \mathrm{~N}$ load: (a) dot mapping of surface composite graphite/LM24 fabricated at 1,400 rpm, (b) worn surface of surface composite (graphite + tin)/LM24 fabricated at 1,000 rpm, and (c) worn surface of counterbody slid against surface composite graphite/LM24 fabricated at 1,000 rpm. 

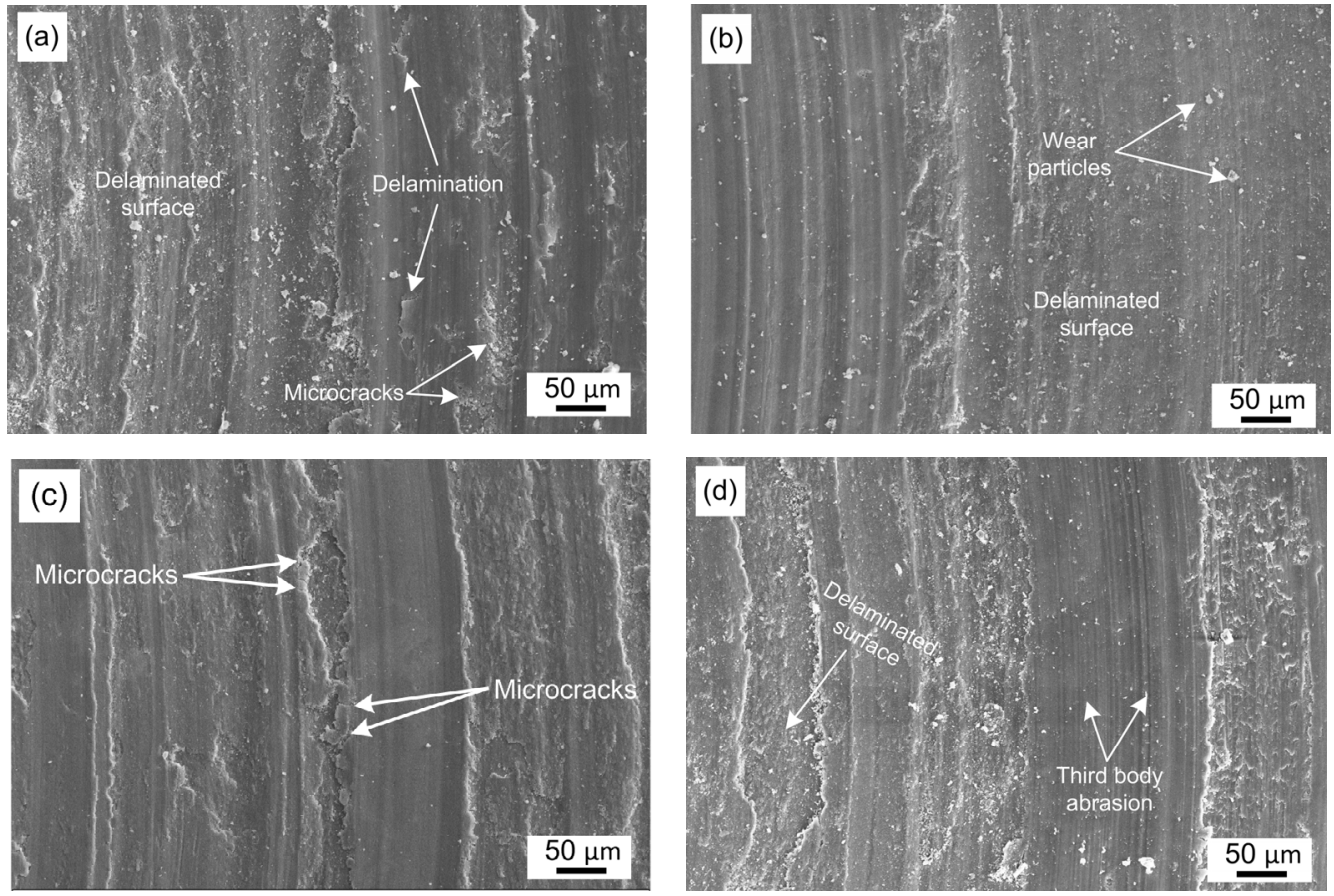

Fig. 10 SEM micrograph of worn surface of base alloy and surface composites at $20 \mathrm{~N}$ load: (a) surface composite graphite/ LM24 fabricated at 1,400 rpm, (b) surface composite (graphite + tin)/LM24 fabricated at 1,400 rpm, (c) surface composite (graphite + tin)/LM24 fabricated at 1,000 rpm, and (d) surface composite graphite/LM24 fabricated at 1,000 rpm.

The wear debris particles from the sliding on the base alloy were large and randomly cracked, as shown in Fig. 11(a). The morphology of the wear debris indicates that the material was removed from the base alloy through adhesive wear. The graphite/LM24 surface composite fabricated at 1,400 rpm had fine and large wear debris, as shown in Fig. 11(b). The fine debris originated from the break-up of the tribolayer or from the crushing of the large trapped wear debris. The graphite in the matrix provided the lubricating effect and prevented the direct metal to metal contact, which limited the adhesive wear severity. The material transferred onto the counterbody when sliding against the graphite/LM24 surface composite fabricated at 1,000 rpm is shown in Fig. 11(c). The transferred material was removed from the unstable tribolayer by adhesive wear. The EDS analysis indicated the presence of high oxygen and aluminum content and limited iron content in the transferred material.

In summary, the sliding of steel counterbody on the graphite-containing LM24 composite surface formed through the FSP resulted in the deformation and abrasion of the aluminum alloy matrix followed by pull-out of the graphite particles. Continued sliding resulted in the crushing and oxidation of the wear debris to form a compact layer during contact. The pulled-out graphite particles lubricated the tribolayer. Based on the experimental results obtained in the present study, the nature of the tribolayer was affected by the (i) graphite particle distribution and (ii) sliding load. In case of uniform distribution, the pulled-out particles were easily interconnected and smeared to form a layer during contact. However, the layer cracked and became unstable at high loads during sliding. A plausible mechanism of the tribolayer formation on the graphite/LM24 composite surface formed by the FSP during sliding against a steel counterbody is shown in Fig. 12. The lubricating tribolayer was continuous and prevented direct metal to metal contact at a low sliding load $(5 \mathrm{~N})$ for high-speed (1,400 rpm) FSP composites containing uniformly distributed graphite particles (Fig. 12(a)). In contrast, the clustered and weakly bonded graphite particles in composites fabricated at low speed of 1,000 rpm formed a discontinuous layer, which became unstable at higher sliding loads due to possibly increased presence of fatigue-induced cracks. Thus, a discontinuous and unstable layer was found on the surfaces of the 
FSP composites produced at low speed (1,000 rpm) during sliding at high load $(20 \mathrm{~N})$, as shown in Fig. 12(b). In the case of composites with (graphite + tin) reinforcement, the formation of the lubricating layer was limited by the presence of the metallic tin particles during contact.
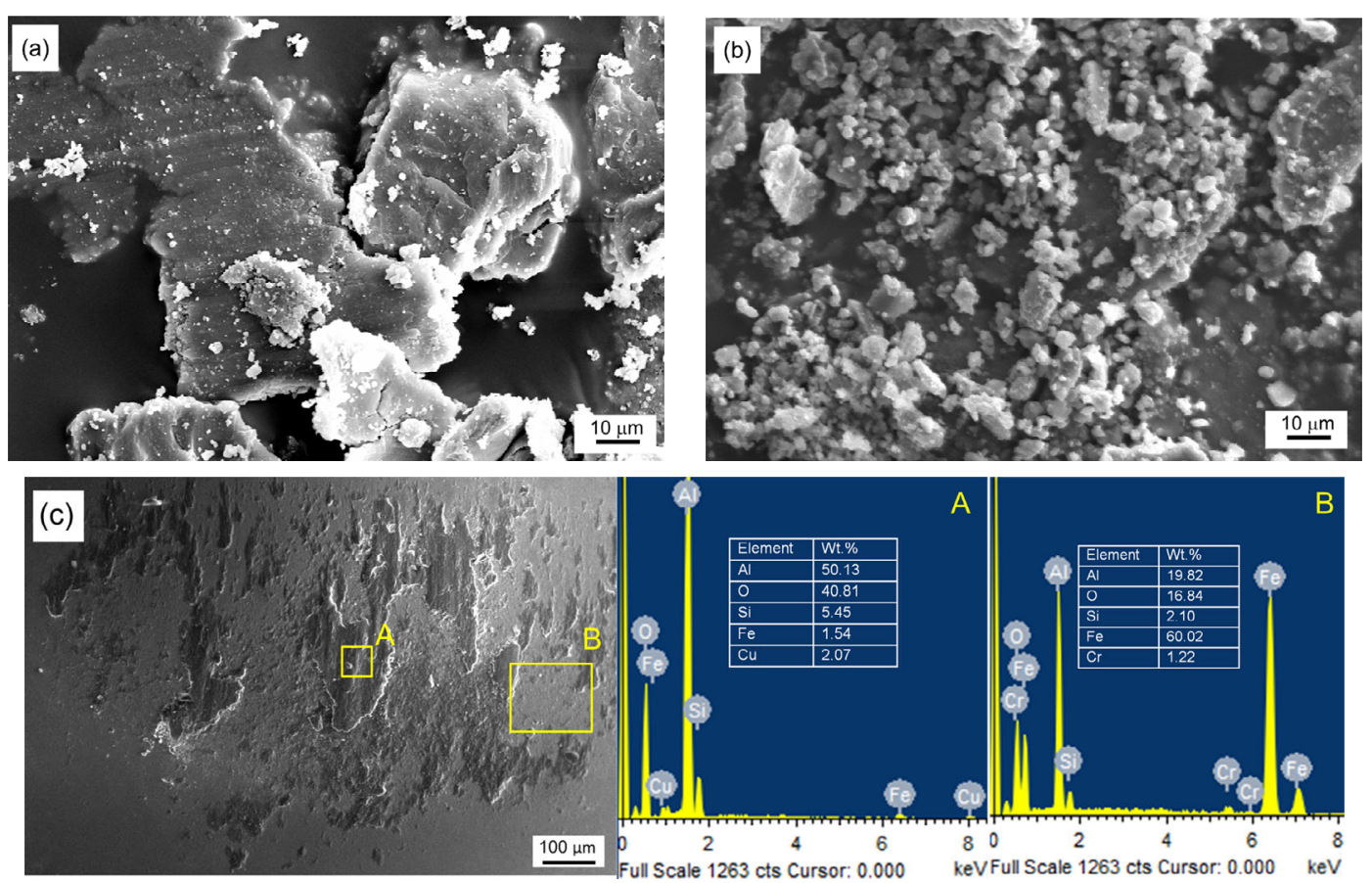

Fig. 11 SEM micrograph of wear debris generated at $20 \mathrm{~N}$ load: (a) base alloy, (b) surface composite graphite/LM24 fabricated at 1,400 rpm, and (c) worn surface and EDS analysis of counterbody slid against surface composite (graphite + tin)/ LM24 fabricated at 1,000 rpm.

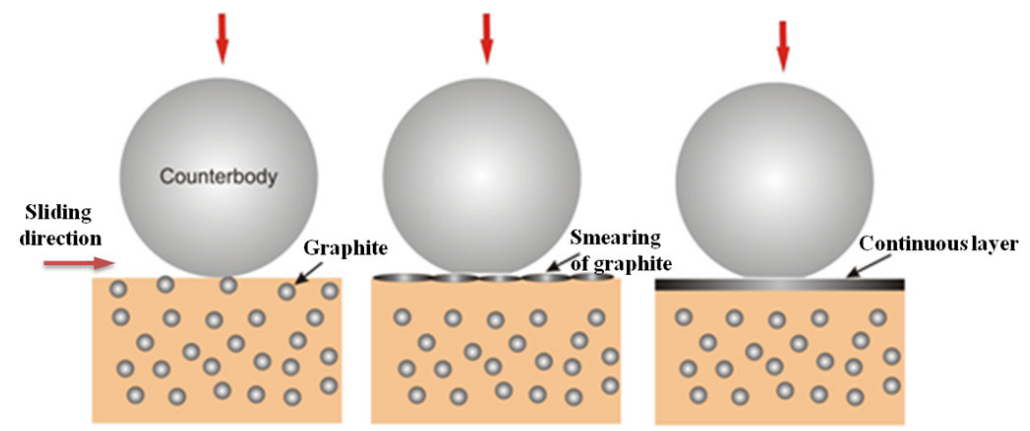

(a)
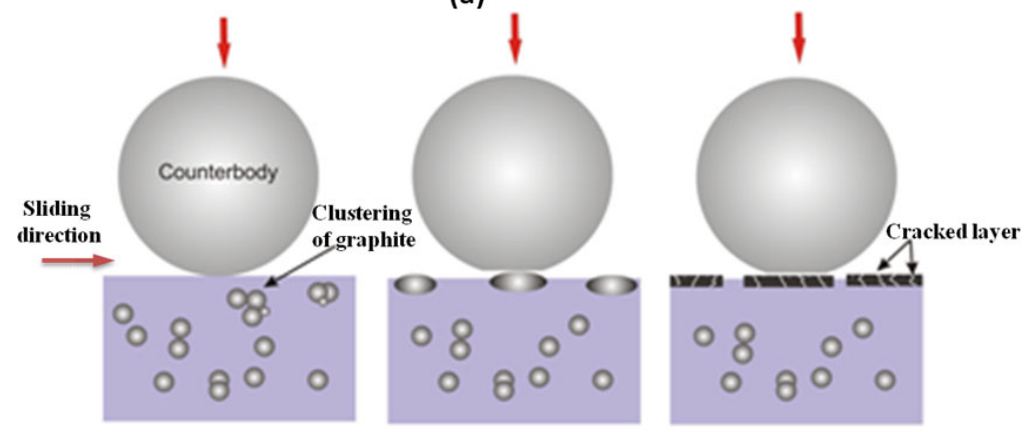

(b)

Fig. 12 Schematic representation of the formation of (a) continuous and stable lubricating layer on the surface of high-speed $(1,400 \mathrm{rpm})$ FSP composite in sliding at low load $(5 \mathrm{~N})$ and $(\mathrm{b})$ discontinuous and unstable lubricating layer on the surface of low-speed (1,000 rpm) FSP composite in sliding at high load (20 N). Counterbody: steel ball. 


\section{Conclusions}

Surface composites were fabricated by reinforcing LM24 alloy with graphite only, and graphite and tin via FSP at two rotational speeds of 1,000 and $1,400 \mathrm{rpm}$. The tribological performance under unlubricated sliding conditions at loads of 5 and $20 \mathrm{~N}$ against a steel ball was discussed in relation to the rotational speed and reinforcement. The following major conclusions were drawn from the present study:

1) The surface composites had microhardness values in the range of 106-118 HV, which were lower than that of the base alloy LM24 of $120 \mathrm{HV}$. The decrease in the microhardness was due to the homogeneous distribution of the softer particles and breaking up of the acicular eutectic Si during the FSP.

2) The lubrication effect when graphite only was used as a reinforcement reduced wear. The graphite/ LM24 surface composite fabricated at 1,400 rpm had a lower COF and wear compared to the base alloy and other surface composites. However, the wear increased with increase in the load.

3) The graphite/LM24 surface composite fabricated at 1,000 rpm had higher wear and friction compared to the composite fabricated at 1,400 rpm. The higher rotational speed increased the shattering effect and heat in the SZ, which enhanced the material flow and reduced wear.

4) The worn surface analysis indicated that material transfer, abrasion, flow wear, and delamination wear were the dominant mechanisms by which material was removed from the base alloy. The abrasion, adhesion, layer formation, and delamination were observed on the worn composite surfaces. High speed $(1,400 \mathrm{rpm})$ during the FSP and a low load (5 N) during sliding, and low speed (1000 rpm) during the FSP and a high load $(20 \mathrm{~N})$ during sliding resulted in the formation of a continuous and stable lubricating layer, and discontinuous and unstable lubricating layer in the contact, respectively.

\section{Acknowledgements}

One of the authors (VS) acknowledges the support of INSPIRE fellowship program, DST, Government of India. Author BVMK acknowledges the partial support of FIG-A scheme of IIT Roorkee, India.

Open Access This article is licensed under a Creative Commons Attribution 4.0 International License, which permits use, sharing, adaptation, distribution and reproduction in any medium or format, as long as you give appropriate credit to the original author(s) and the source, provide a link to the Creative Commons licence, and indicate if changes were made.

The images or other third party material in this article are included in the article's Creative Commons licence, unless indicated otherwise in a credit line to the material. If material is not included in the article's Creative Commons licence and your intended use is not permitted by statutory regulation or exceeds the permitted use, you will need to obtain permission directly from the copyright holder.

To view a copy of this licence, visit http://creativecommons.org/licenses/by/4.0/.

\section{References}

[1] Scepanovic J, Asanovic V, Herenda S, Vuksanovic D, Radonjic D, Korac F. Microstructural characteristics, mechanical properties, fracture analysis and corrosion behavior of hypereutectic Al-13.5 Si alloy. Int $J$ Metalcast 13(3): 700-714 (2019)

[2] Patel S K, Singh V P, Kuriachen B. Microstructural, Tribological and mechanical properties evolution of $\mathrm{ZrSiO}_{4} / \mathrm{A} 4047$ surface composite fabricated through friction stir processing. Trans Indian Inst Met 72(7): 1765-1174 (2019)

[3] Park J, Yeo I, Jang I, Jeong S. Improvement of friction characteristics of cast aluminum-silicon alloy by laser shock peening. J Mater Process Technol 266: 283-291 (2019)

[4] Singla Y K, Chhibber R, Avdesh, Goyal S, Sharma V. Influence of single and dual particle reinforcements on the corrosion behavior of aluminum alloy based composites. Proc Inst Mech Eng, Part L: J Mater: Des Appl 232(6): 520-532 (2018)

[5] Summer F, Grün F, Offenbecher M, Taylor S. Challenges of friction reduction of engine plain bearings-Tackling the problem with novel bearing materials. Tribol Int 131: 238-250 (2019)

[6] Rao AG, Deshmukh VP, Prabhu N, Kashyap BP. Ductilizing of a brittle as-cast hypereutectic Al-Si alloy by friction 
stir processing. Mater Lett 159: 417-419 (2015)

[7] Guru PR, Khan F, Panigrahi SK, Ram GDJ. Enhancing strength, ductility and machinability of a Al-Si cast alloy by friction stir processing. J Manuf Process 18: 67-74 (2015)

[8] Ceschini L, Morri A, Toschi S, Seifeddine S. Room and high temperature fatigue behaviour of the A354 and C355 (Al-Si-Cu-Mg) alloys: Role of microstructure and heat treatment. Mater Sci Eng: A 653: 129-138 (2016)

[9] Sharma V, Prakash U, Kumar B V M. Surface composites by friction stir processing: A review. J Mater Process Technol 224: 117-134 (2015)

[10] Sharma V, Gupta Y, Kumar B V M, Prakash U. Friction stir processing strategies for uniform distribution of reinforcement in a surface composite. Mater Manuf Process 31(10): 1384-1392 (2016)

[11] Wang H T, Fang Z Z, Sun P. A critical review of mechanical properties of powder metallurgy titanium. Int J Powder Metall 46(5): 45-57 (2010)

[12] Yuvaraj N, Aravindan S, Vipin. Comparison studies on mechanical and wear behavior of fabricated aluminum surface nano composites by fusion and solid state processing. Surf Coat Technol 309: 309-319 (2017)

[13] Tutunchilar S, Givi M K B, Haghpanahi M, Asadi P. Eutectic Al-Si piston alloy surface transformed to modified hypereutectic alloy via FSP. Mater Sci Eng: A 534: 557-567 (2012)

[14] Yang R, Zhang Z Y, Zhao Y T, Chen G, Guo Y H, Liu M $\mathrm{P}$, Zhang J. Effect of multi-pass friction stir processing on microstructure and mechanical properties of $\mathrm{Al}_{3} \mathrm{Ti}$ / A356 composites. Mater Characteriz 106: 62-69 (2015)

[15] Akbari M, Shojaeefard M H, Asadi P, Khalkhali A. Wear performance of A356 matrix composites reinforced with different types of reinforcing particles. J Mater Eng Perform 26(9): 4297-4310 (2017)

[16] Yi L F, Yoshida N, Yamamoto T, Onda T, Chen Z C. Microstructure and thermal/mechanical properties of hot-extruded aluminum/graphite composites with Al-Si alloy addition. J Mater Sci 54(13): 9933-9944 (2019)

[17] Su L L, Gao F, Han X M, Fu R, Zhang E. Tribological behavior of copper-graphite powder third body on copper-based friction materials. Tribol Lett 60(2): 30 (2015)

[18] Zhu J J, Qi J H, Guan D K, Ma L, Dwyer-Joyce R. Tribological behaviour of self-lubricating $\mathrm{Mg}$ matrix composites reinforced with silicon carbide and tungsten disulfide. Tribol Int 146: 106253 (2020)

[19] Wang Y R, Gao Y M, Li Y F, Li M T, Sun L, Zhai W Y, Li K M. Research on synergistic lubrication effect of silver modified $\mathrm{Cu}-\mathrm{Ni}$-graphite composite. Wear 444445: 203140 (2020)

[20] Qiu J, Baker I, Kennedy F E, Liu Y, Munroe P R. The effects of stoichiometry on the dry sliding wear of FeAl. Intermetallics 40: 19-27 (2013)

[21] Baradeswaran A, Perumal A E. Effect of graphite on tribological and mechanical properties of AA7075 composites. Tribol Trans 58(1): 1-6 (2015)

[22] Sarmadi H, Kokabi A H, Reihani S M S. Friction and wear performance of copper-graphite surface composites fabricated by friction stir processing (FSP). Wear 304 (1-2): 1-12 (2013)

[23] Mahdavi S, Akhlaghi F. Effect of the graphite content on the tribological behavior of $\mathrm{Al} / \mathrm{Gr}$ and $\mathrm{Al} / 30 \mathrm{SiC} / \mathrm{Gr}$ composites processed by in situ powder metallurgy (IPM) method. Tribol Lett 44(1): 1-12 (2011)

[24] Marcinauskas L, Mathew J S, Milieška M, Aikas M, Kalin M. Effect of graphite concentration on the tribological performance of alumina coatings. J Alloy Compd 827: 154135 (2020)

[25] Raghuram H, Katsich C, Pichelbauer K, Koschatzky K, Gachot C, Cihak-Bayr U. Design of wear and corrosion resistant FeNi-graphite composites by laser cladding. Surf Coat Technol 377: 124897 (2019)

[26] Wu X F, Zhang G A. Effect of Sn addition on microstructure and dry sliding wear behaviors of hypereutectic aluminumsilicon alloy A390. J Mater Sci 46(22): 7319-7327 (2011)

[27] El-Salam F A, El-Khalek A M A, Nada R H, Wahab L A, Zahran H Y. Effect of Sn content on the structural and mechanical properties of Al-Si alloy. Mater Sci Eng: A 527(4-5): 1223-1229 (2010)

[28] Devaraju A, Kumar A, Kotiveerachari B. Influence of rotational speed and reinforcements on wear and mechanical properties of aluminum hybrid composites via friction stir processing. Mater Des 45: 576-585 (2013)

[29] Kanchanomai C, Saengwichian B, Manonuku A. Delamination wear of metal injection moulded $316 \mathrm{~L}$ stainless steel. Wear 267(9-10): 1665-1672 (2009)

[30] Yadav R K S, Sharma V, Kumar B V M. On the role of sliding load and heat input conditions in friction stir processing on tribology of aluminium alloy-alumina surface composites. Tribol-Mater, Surf Interf 13(2): 88-101 (2019) 


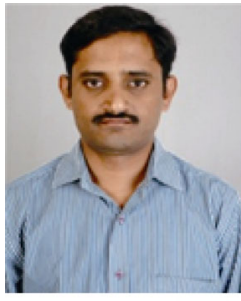

B. Venkata MANOJ KUMAR. He is currently working as an associate professor at the Department of Metallurgical and Materials Engineering,

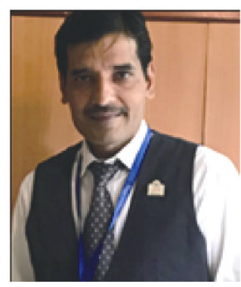

Vipin SHARMA. He is currently working as an assistant professor at the Department of Mechanical Engineering, Sagar Institute of Research Technology and Science, Bhopal. He received his bachelor's degree in mechanical engineering in 2008 from

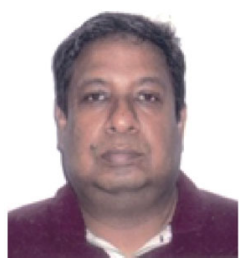

Ujjwal PRAKASH He is currently a professor in Department of Metallurgical and Materials Engineering, Indian Institute of Technology (IIT)
Indian Institute of Technology (IIT) Roorkee. Dr. Manoj works in understanding the microstructure mechanical property-wear relation of important ceramics/cermets and composites.

Rajiv Gandhi Proudyogiki Vishwavidyalaya, Bhopal, India. He achieved his master degree in metallurgical and materials engineering at Thapar University, Patiala in 2011. He obtained his Ph.D. degree from IIT Roorkee in 2015. His research interest includes solid state processing of metal matrix composites and their tribology.

Roorkee. Dr. Ujjwal Prakash works on superalloys, ODS steels, and processing of materials. 